\title{
Whole-Genome DNA Methylation Analysis in Hydrogen Peroxide Overproducing Transgenic Tobacco Resistant to Biotic and Abiotic Stresses
}

\author{
Ana L. Villagómez-Aranda ${ }^{1}$ (D), Luis F. García-Ortega ${ }^{2}$, Irineo Torres-Pacheco ${ }^{1}$ \\ and Ramón G. Guevara-González ${ }^{1, * \text { (D) }}$ \\ 1 Biosystems Engineering Group, Engineering Faculty, Amazcala Campus, The Autonomous University of \\ Querétaro, Highway Chichimequillas s/n Km 1, Amazcala, El Marqués, Querétaro C.P. 76265, Mexico; \\ annvillaranda@gmail.com (A.L.V.-A.); torresirineo@gmail.com (I.T.-P.) \\ 2 Department of Genetic Engineering, Center for Research and Advanced Studies of the National Polytechnic \\ Institute (Cinvestav), Highway Irapuato-Leon, $\mathrm{Km}$ 9.6, Libramiento norte, Irapuato, \\ Guanajuato C.P. 36821, Mexico; luis.garcia@cinvestav.mx \\ * Correspondence: ramon.guevara@uaq.mx
}

check for

updates

Citation: Villagómez-Aranda, A.L.; García-Ortega, L.F.; Torres-Pacheco, I.; Guevara-González, R.G.

Whole-Genome DNA Methylation Analysis in Hydrogen Peroxide Overproducing Transgenic Tobacco Resistant to Biotic and Abiotic Stresses. Plants 2021, 10, 178. https://doi.org/10.3390/plants 10010178

Received: 12 November 2020 Accepted: 30 December 2020 Published: 19 January 2021

Publisher's Note: MDPI stays neutral with regard to jurisdictional clai$\mathrm{ms}$ in published maps and institutional affiliations.

Copyright: (C) 2021 by the authors. Licensee MDPI, Basel, Switzerland. This article is an open access article distributed under the terms and conditions of the Creative Commons Attribution (CC BY) license (https:// creativecommons.org/licenses/by/ $4.0 /)$.
Abstract: Epigenetic regulation is a key component of stress responses, acclimatization and adaptation processes in plants. DNA methylation is a stable mark plausible for the inheritance of epigenetic traits, such that it is a potential scheme for plant breeding. However, the effect of modulators of stress responses, as hydrogen peroxide $\left(\mathrm{H}_{2} \mathrm{O}_{2}\right)$, in the methylome status has not been elucidated. A transgenic tobacco model to the CchGLP gene displayed high $\mathrm{H}_{2} \mathrm{O}_{2}$ endogen levels correlated with biotic and abiotic stresses resistance. The present study aimed to determine the DNA methylation status changes in the transgenic model to obtain more information about the molecular mechanism involved in resistance phenotypes. The Whole-genome bisulfite sequencing analysis revealed a minimal impact of overall levels and distribution of methylation. A total of 9432 differential methylated sites were identified in distinct genome regions, most of them in CHG context, with a trend to hypomethylation. Of these, 1117 sites corresponded to genes, from which 83 were also differentially expressed in the plants. Several genes were associated with respiration, energy, and calcium signaling. The data obtained highlighted the relevance of the $\mathrm{H}_{2} \mathrm{O}_{2}$ in the homeostasis of the system in stress conditions, affecting at methylation level and suggesting an association of the $\mathrm{H}_{2} \mathrm{O}_{2}$ in the physiological adaptation to stress functional linkages may be regulated in part by DNA methylation.

Keywords: DNA methylation; hydrogen peroxide; hypomethylation

\section{Introduction}

Plants are regularly exposed to stress factors, and due to their sessile nature, they have developed sophisticated defense responses at a physiological, biochemical, and genetic level. It is well known that the environment and the genotype give the phenotype of an organism. This is partly due to the epigenetic phenomena, where modifications in DNA, RNA, and histones can alter the genetic expression patterns of genes. The environment determines these modifications; they are labile but can be stable and heritable [1,2]. Therefore, the epigenetic modifications are part of the genetic plasticity of organisms [3] and in plants are also essential in acclimatization (stable during the same generation) and adaptation processes (conservable to subsequent generations) [4].

The DNA modifications include C5-methylcytosine $(5 \mathrm{mC})$, N6-methyladenine $(6 \mathrm{~mA})$, and N4-methylcytosine $(4 \mathrm{mC})$ [5]. There are some other DNA modifications as the O6methylguanine (O6-mG), N7-methylguanine $(7 \mathrm{mG})$ or N3-methyladenine (N3mA) that are believed to be cause by endogenous and/or environmental alkylating agents [6] and are emerging as important markers with adverse effects. $5 \mathrm{mC}$ methylation is the most abundant and studied. As mentioned, in plants, the $5 \mathrm{mC}$ presence ranges from 5 to 
$30 \%$ depending on the species [7], while others, as the $6 \mathrm{~mA}$ levels are less than $0.8 \%$ in eukaryotes and in Arabidopsis has been reported as less than $0.2 \%$ [5]. In plants, the $5 \mathrm{mC}$ DNA methylation exists in three different sequence contexts: CG, CHG, and CHH. The CG context takes place in dinucleotides $\mathrm{C}$ and $\mathrm{G}$, and it is called symmetrical context. For the $\mathrm{CHG}$ and $\mathrm{CHH}$ contexts, the $\mathrm{H}$ can be any base as $\mathrm{A}, \mathrm{T}$, or $\mathrm{C}[8,9]$. The accumulation of DNA methylation in all contexts results in chromatin condensation and, therefore, gene silencing [8].

DNA methylation is involved in the replication and mismatch repair, the control in gene expression, tissue-specific gene expression, transcript synthesis, signaling to hostpathogen interaction, virus resistance, gene imprinting, and epigenetic memory [5]. DNA methylation is a highly stable epigenetic mark, due to it can be maintained during the mitotic and meiotic cell division processes, such that these changes provide a mark plausible for the inheritance of metastable epigenetic traits [9-11]. In plants, DNA methylation alterations occurs as part of the response to stress factors as drought [12], salinity [7,13], cold-stress [14], heat-stress, presence of heavy metals [15], nutriment deficit [16,17], wounding [18], viral infection [19] pathogen attack [20] and even spaceflight [21]. Similarly, the priming with some compounds alters the DNA methylation behavior of the plant. $\beta$-Aminobutyric acid (BABA) [22] and methyl jasmonate (MeJA) [23] induce DNA hypermethylation, and it is suggested that it may be associated with the development of memory to enhance stress tolerance. Due to this nature of the epigenetic changes, they are a potential strategy for plant breeding to obtain more adaptable crops to stress. Further, it is necessary to elucidate what kind and doses of stress factors can induce an epigenomic response in the plant genome.

Hydrogen peroxide $\left(\mathrm{H}_{2} \mathrm{O}_{2}\right)$ is an essential compound in stress perception and signaling. It interacts with the $\mathrm{Ca}^{2+} / \mathrm{K}^{+}$channels, phytohormones such as abscisic acid (ABA) and Salicylic acid (SA), MAP kinases, miRNAs, and transcription factors that lead to the activation of stress-related genes [24-26]. It is considered a modulator of the stress response and immunity pathways in plants since the exogenous application of $\mathrm{H}_{2} \mathrm{O}_{2}$ can improve the responses to stress [27] as shown in several studies with a positive effect on tolerance to saline stress [28-31], drought [32,33], high temperatures [34,35], flooding [36], virus infection [37,38] and low lighting conditions [39].

Our research group has a model to study the effects of $\mathrm{H}_{2} \mathrm{O}_{2}$ in plant stress responses: a transgenic Nicotiana tabacum cv. Xanthi line overproducing $\mathrm{H}_{2} \mathrm{O}_{2}$ constitutively. This is due to the expression of the transgene CchGLP of Capsicum chinense Jacq, which encodes for an Mn-superoxide dismutase (Mn-SOD). The CchGLP gene is involved in the natural resistance to geminivirus in accession BG-3821 of C. chinense from Yucatán, México [40]. The expression of CchGLP in Nicotiana tabacum xanthi nc resulted in several transgenic lines, of which two lines stood out: Line 8 (L8) with a high gene expression and high $\mathrm{H}_{2} \mathrm{O}_{2}$ production; and Line 1 (L1) with low gene expression and low $\mathrm{H}_{2} \mathrm{O}_{2}$ production, which is considered as azygous control. Both transgenic lines presented a characteristic phenotype against biotic and abiotic stress of resistance and susceptibility, respectively, to geminivirus infection [41], drought [42], and heavy metals [43]. In previous works, different omic profiles were determined to elucidate the molecular elements involved in the resistance phenotype of the transgenic line at different molecular levels: proteomic [44], metabolomic [44], transcriptomic [42], and miRNAs profiles [43]. The L8 has shown a higher occurrence of metabolism and cell growth and differentiation-related proteins, and metabolites related to phenylpropanoid metabolism, osmotic process, and amino acid metabolisms [42]. Likewise, the differential transcriptomic between these two lines displayed genes associated with primary metabolism and cellular functions as cell wall reinforcement and secondary metabolism as phenylpropanoids, terpenoids, alkaloids, and steroid hormone biosynthesis [44,45]. In the case of the miRNAs differential profile, the results were associated mainly with the structural molecular activity and protontransporting type ATPase [43]. 
It has been suggested that epigenetic marks may have a connection with signaling reactive oxygen species (ROS) and redox metabolism, due to it has been observed that the enzymes responsible for histone methylation are sensitive to the production of ROS [46,47]. However, no studies have been conducted on the effect of $\mathrm{H}_{2} \mathrm{O}_{2}$ on epigenetic mechanisms in plants. Therefore, the present study aimed to determine changes in the 5-methylcytosine DNA methylation status of the transgenic tobacco $\mathrm{H}_{2} \mathrm{O}_{2}$ overproducing line (L8), which has resistance to biotic and abiotic stresses in comparison with the azygous stress-susceptible control (L1). This knowledge could be a fundamental insight into the role of the epigenetic plant strategies used in the adaptation to stress conditions, and the role of the $\mathrm{H}_{2} \mathrm{O}_{2}$ in the physiological adaptation, with the expectation of being applied to enhance the plant tolerance to changing environments.

\section{Results}

\subsection{Phenotypic Characteristics}

L8 (overproducing $\mathrm{H}_{2} \mathrm{O}_{2}$ ) and L1 (azygotic line) have typical growth under the experimental conditions used, as shown in Figure 1. L8 displayed a slight growth delay compared with L1, likely associated with the energy demands of its phenotype. However, there were no significant differences in height, fresh weight, foliar area, stem diameter, and chlorophyll content, as described in Table 1. Therefore, as mentioned in previous works, the $\mathrm{H}_{2} \mathrm{O}_{2}$ overproduction levels in L8 do not significantly affect the growth and morphology of plants during their life cycle.

A

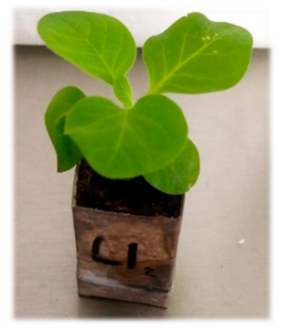

B

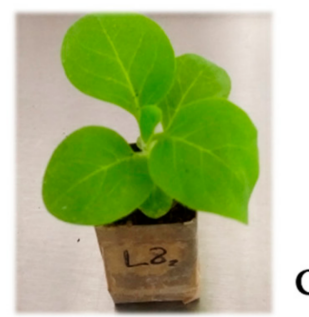

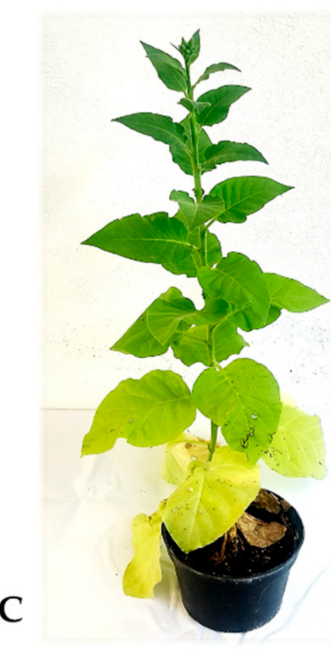

D

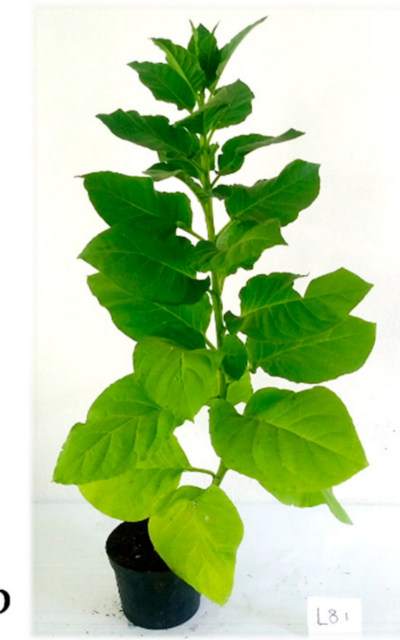

Figure 1. Phenotype of transgenic tobacco plants. In the photos, there is shown the phenotype characteristics of the transgenic plants in two physiological ages. The first, at 6-weeks-old both plants (A) L1 and (B) L8 were practically identical. At this age, samples were taken for the WGBS. At 3-months-old, both plants still looked similar, but the plants (C) L1 presented a light yellowing in the basal leaves compared with the (D) L8 plant.

Table 1. Physiological features.

\begin{tabular}{ccccc}
\hline Feature & L8 (6 Weeks) & L8 (3 Months) & L1 (6 Weeks) & L1 (3 Months) \\
\hline Height $(\mathrm{cm})$ & $6.4 \pm 0.51$ & $72 \pm 3.46$ & $7.1 \pm 0.24$ & $74 \pm 1.0$ \\
Fresh weight leaves $(\mathrm{g})$ & $0.55 \pm 0.03$ & $41.6 \pm 4.19$ & $0.57 \pm 0.02$ & $56.9 \pm 3.43$ \\
Fresh weight root $(\mathrm{g})$ & $0.12 \pm 0.02$ & $25.9 \pm 5.23$ & $0.13 \pm 0.01$ & $28.2 \pm 2.68$ \\
Stem width $(\mathrm{mm})$ & $1.54 \pm 0.11$ & $11.3 \pm 0.12$ & $1.52 \pm 0.14$ & $10.8 \pm 0.22$ \\
Leaf area $\left(\mathrm{cm}^{2}\right)$ & $47.5 \pm 3.7$ & $1775 \pm 313$ & $49.1 \pm 2.9$ & $2607 \pm 134$ \\
SPAD value & $39.4 \pm 2.09$ & $46.7 \pm 2.24$ & $38.2 \pm 2.14$ & $44.8 \pm 2.55$ \\
\hline
\end{tabular}




\subsection{DNA Methylation Levels and Distribution}

To characterize transgenic tobacco methylomes, we generated single-base resolution maps of DNA methylation by whole-genome bisulfite sequencing (WGBS) for 6-week-old plants of both transgenic tobacco lines. Each transgenic line was sequenced with three biological replicates, and every sequencing library was produced and sequenced. It was obtained an average of 461205823 clean reads by each sample, with quality score of Q20 average of $97.73 \%$ (Table S1). The methylomes presented a mapping efficiency with the reference genome in a range between 55 and $71 \%$ of unique alignments per library (Figure S1). The principal methylation context was CG, in both transgenic plants, with $84.6 \%$ for L8 and $85.4 \%$ for L1 (Figure 2A). Also, the lesser abundant context was $\mathrm{CHH}$ with $15.7 \%$ and $14.1 \%$, respectively. This represented an average methylation level of $48.64 \%$ for CG, $42.33 \%$ on CHG, and $9.03 \%$ on $\mathrm{CHH}$ of the total DNA methylation levels in the transgenic line L8 (Figure 2B). However, the general methylation levels and context distribution were not changed noticeably between transgenic lines in normal growth conditions.

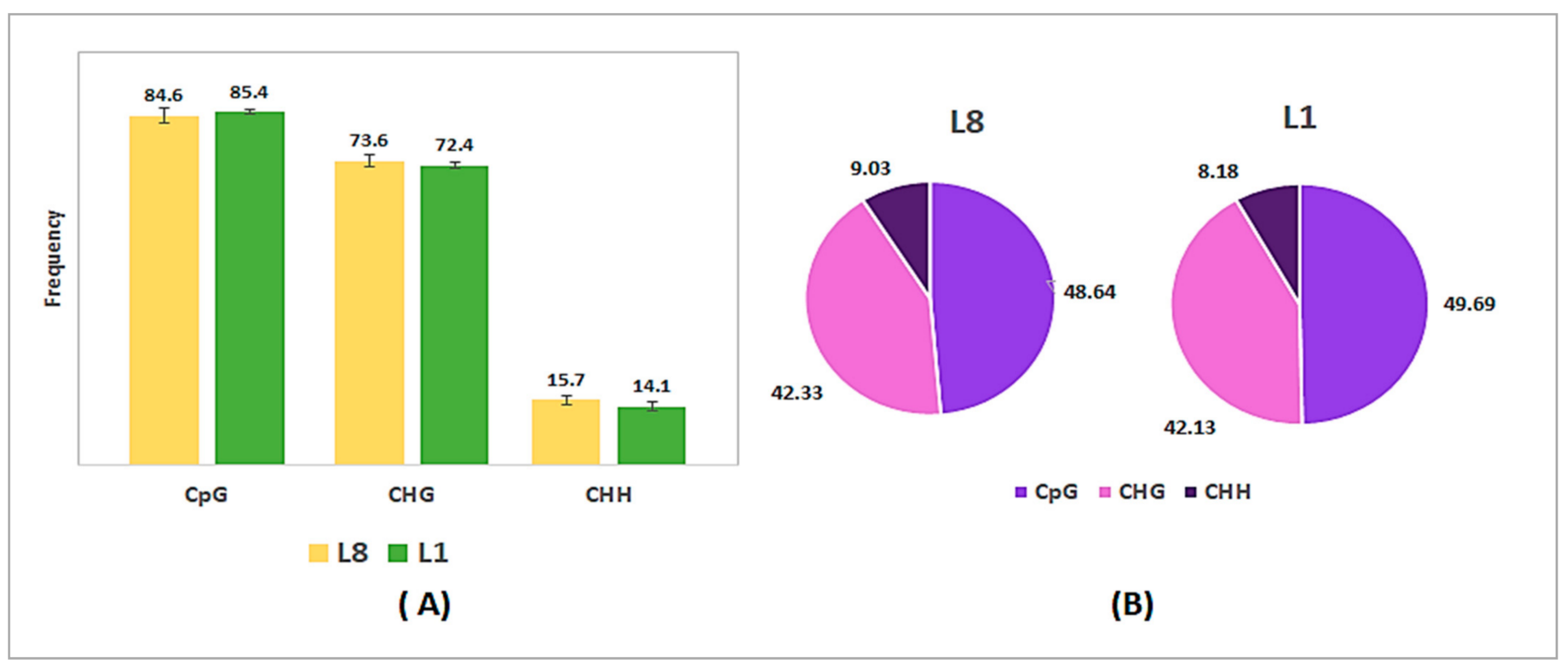

Figure 2. DNA methylation levels in high (L8) and low (L1) $\mathrm{H}_{2} \mathrm{O}_{2}$ producing transgenic tobacco plants by WGBS. (A) Global methylation pattern of transgenic tobacco plants and their (B) Proportion of each context in the total methylation in both lines.

\subsection{Distribution of Differentially Methylated Cytosines}

To examine differences in DNA methylation between the two transgenic line, we compared the cytosines methylated between overproducing (L8) and azygous (L1) plants to define the differentially methylated cytosines (DmCs) as hyper or hypomethylated, according to the methylation proportion of a cytosine between the L1 and L8 samples at the same site. The hypermethylated and hypomethylated cytosines were distributed similarly across the chromosomes of the genome (Figure 3A). The major abundance of hypermethylated cytosines was mapped in chromosomes 11 and 16, while the hypomethylated was in chromosomes 9 and 12 . 


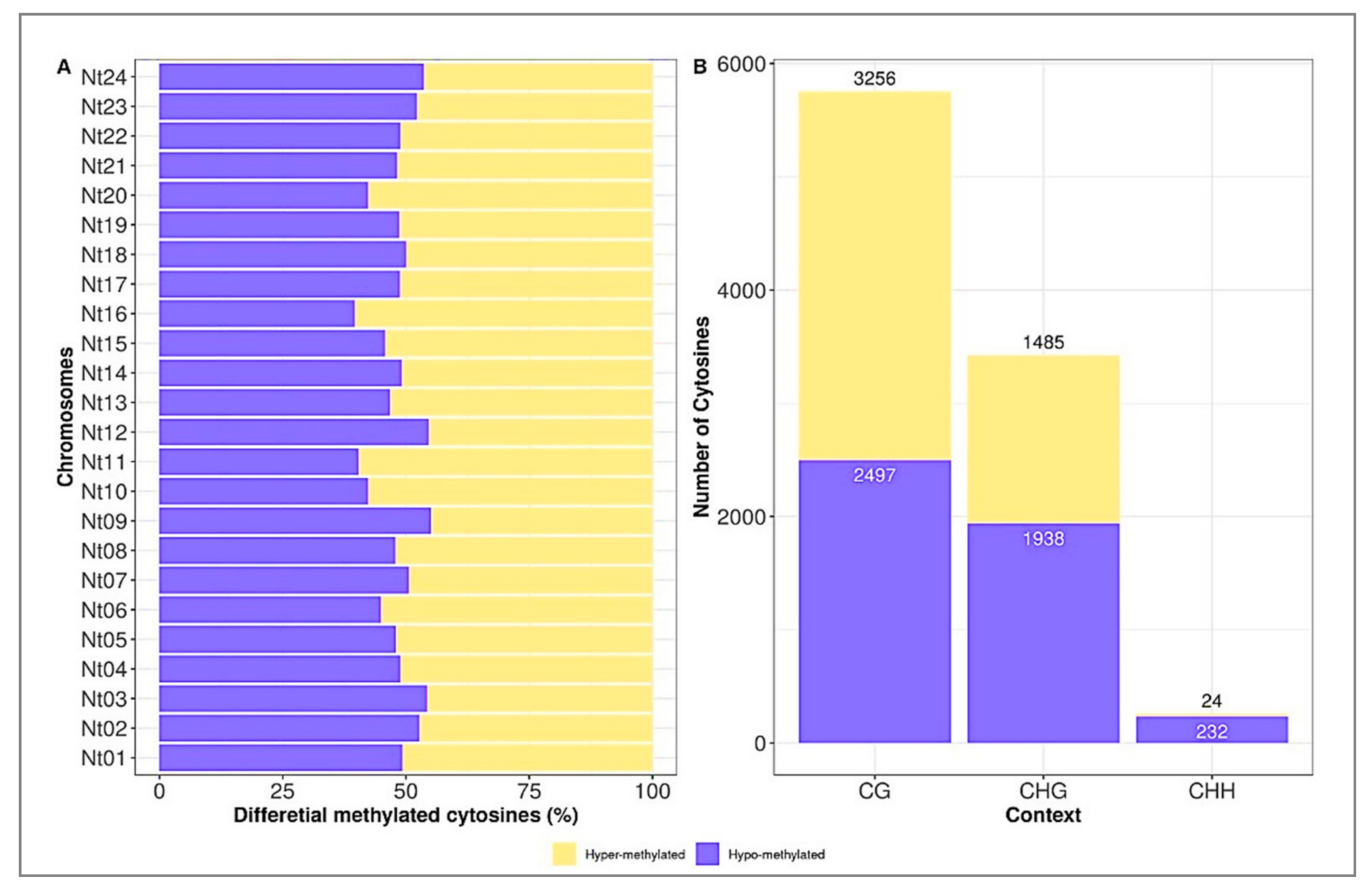

Figure 3. Distribution of relative DmC levels for each chromosome (A) and CG, CHG and CHH context (B) in the high $\mathrm{H}_{2} \mathrm{O}_{2}$ producer transgenic tobaccos.

In total, 9432 DmCs were found, among which 4765 were hyper-methylated, and 4667 were hypomethylated. The higher proportion of DmCs was identified in the CG context, and the lower sites were observed in the $\mathrm{CHH}$ context (Figure 3B). The latter was consistent with the global distribution of DNA methylation patterns of tobacco plants. However, the DmCs distribution in different genomic elements (genes, promoters, introns, intergenic regions, and transposable elements) was variable in each context (Figure 4A-F). The intergenic regions were the most enriched element with methylation in almost all contexts, except by the hypermethylated CHG and CHH contexts. In the CG context, the intergenic regions methylation was $91.34 \%$ and $92.5 \%$ for hyper and hypomethylated DmCs, respectively. In the case of the hypomethylated DmCs in $\mathrm{CHG}$ and $\mathrm{CHH}$ on intergenic regions were $69.8 \%$ and $79.3 \%$. The intron regions were significantly abundant in the hypermethylated DmCs in CHG and CHH contexts, with $43.63 \%$ and $52 \%$, respectively.

In order to identify direct linkages between the DmCs found and the phenotype of the overproducing $\mathrm{H}_{2} \mathrm{O}_{2}$ transgenic tobacco plants, we focused on the DmCs within the proteincoding regions. The higher DmCs on exons was observed in the CHG context (Figure 4B,E), in which 360 DmCs hypermethylated and 636 DmCs hypomethylated were found. By contrast, in the CG context, 107 DmCs hypermethylated and 105 hypomethylated were detected. For the $\mathrm{CHH}$ context, just three DmCs hypermethylated and 23 DmCs hypomethylated were identified. The data of DmCs identified on exons are listed in Tables S2 and S3. 


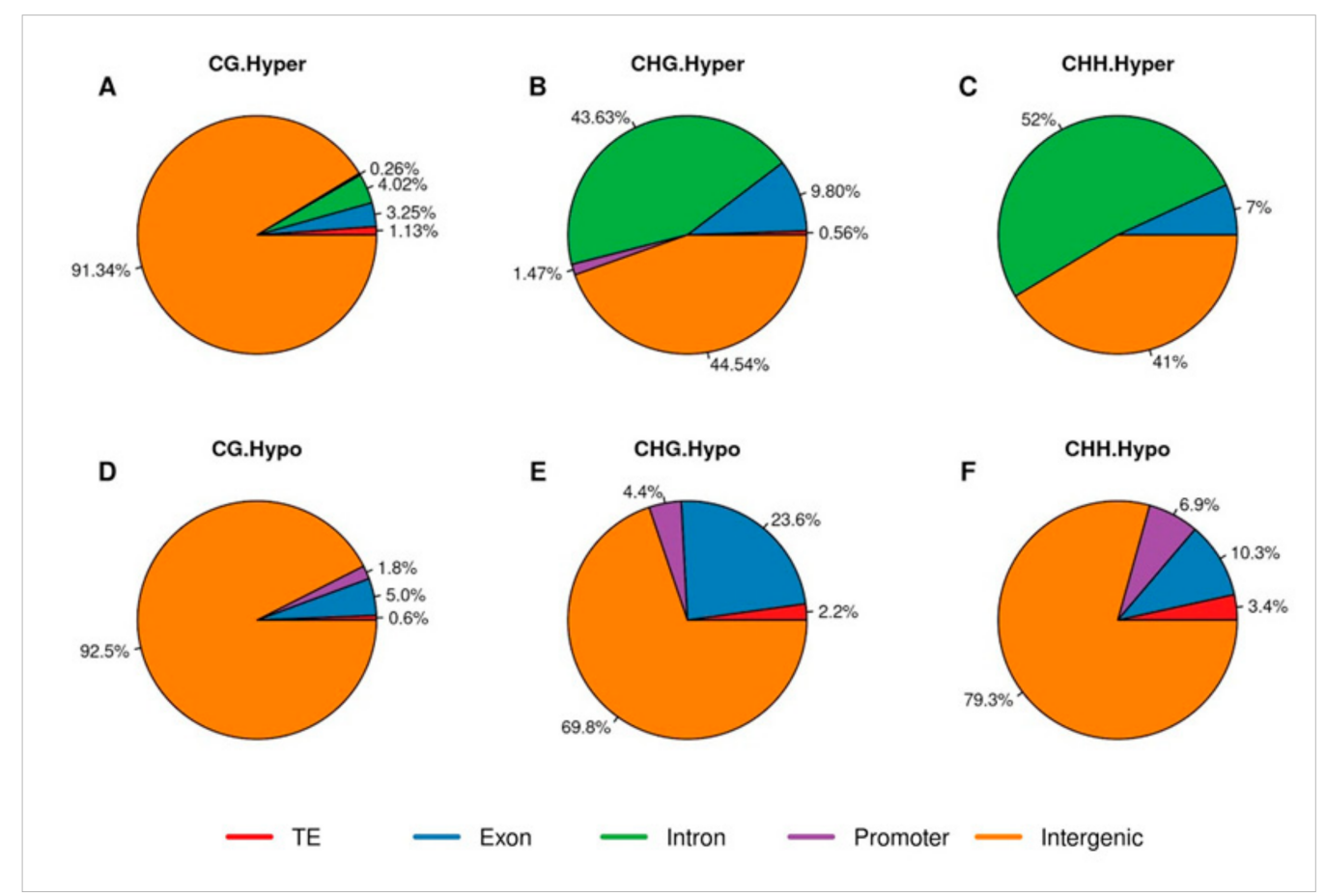

Figure 4. Distribution of genomic elements with hypo-DmCs and hyper-DmCs in the whole genome for each context. (A) hyper-CG. (B) hyper-CHG. (C) hyper-CHH. (D) hypo-CG. (E) hypo-CHG. (F) hypo-CHH. Transposable elements (TE) in red colour; exons in blue colour; introns in green colour; promoter region ( $2 \mathrm{~kb}$ upstream of TSS and $2 \mathrm{~kb}$ downstream of TES) in purple colour; intergenic regions in orange colour.

\subsection{Gene Ontology Analysis}

The gene-ontology analysis applied to the DmCs in protein-coding regions showed enrichment in hypomethylated DmCs on respiratory and energy metabolism (Figure S2). In the category biological process, the functions identified were photosynthetic electron transport chain, photosynthesis, photosynthetic light reactions, generation of precursor metabolites and energy, electron transport chain. In the category molecular function, the hypermethylated DmCs were associated with enrichment for the ADP binding process.

\subsection{Correlation of Differentially Methylated Cytosines and Differential Gene Expression}

The correlation of genes with DmCs and differential expressed Genes (DEGs) was analyzed to determine the biological relevance of the methylome in the physiological adaptation to stress. For this analysis, $1117 \mathrm{DmCs}$ sites were considered, including the sites on protein-coding regions and promoter regions. Also, there were considered the data set of DEGs [42] and small-RNA targets (sRNA) [43] obtained in previous works, considering that the same grown conditions were used in the experiments and the physiological age of plants tested were identical. Of the genes differentially expressed in response to $\mathrm{H}_{2} \mathrm{O}_{2}$ in the transgenic tobaccos, 5397 DEGs were considered, and among those, 83 genes were also differentially methylated (Figure 5A). Most of the genes were methylated in the gene body in the CHG context, where they tended to hypomethylation, as mentioned in previous sections (Figure 5B). 


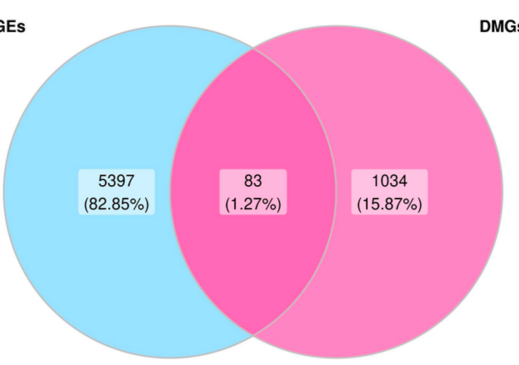

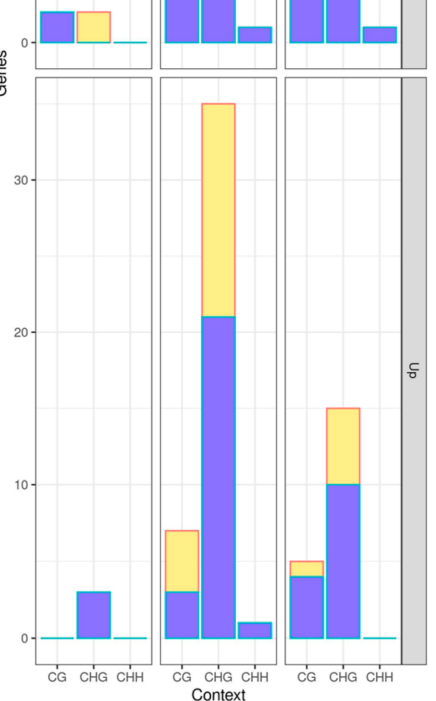

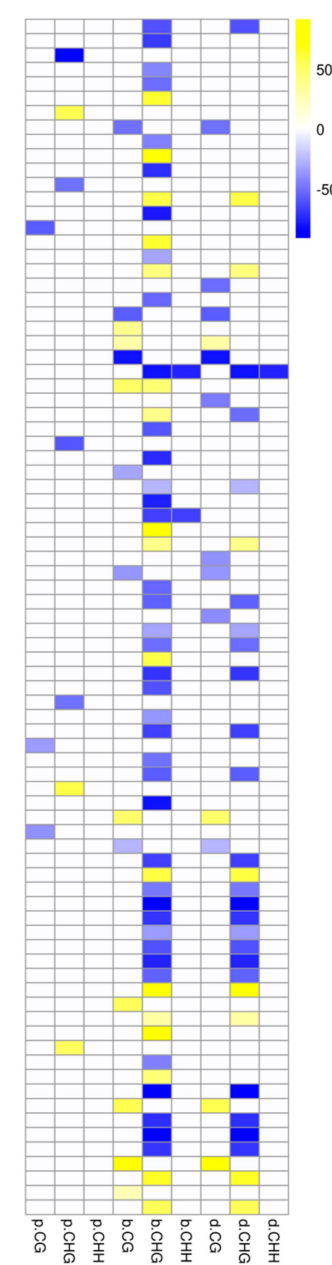

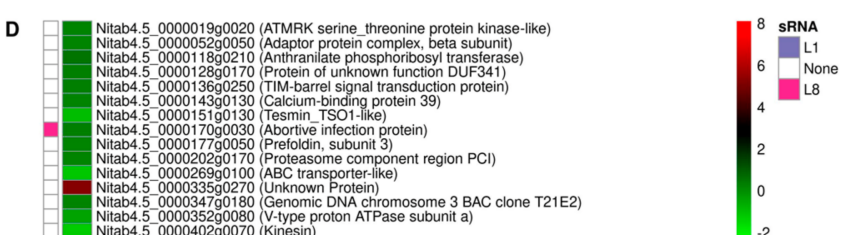

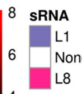

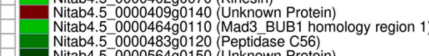

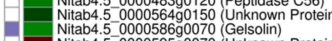
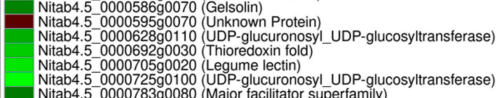

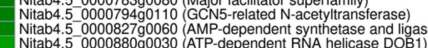

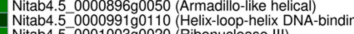

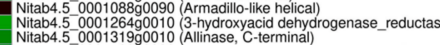

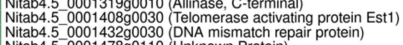

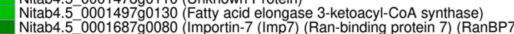

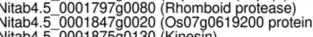

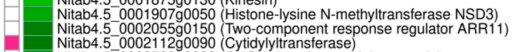

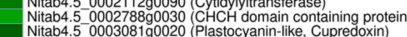

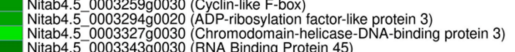

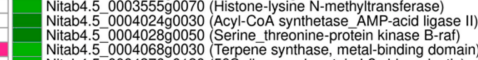

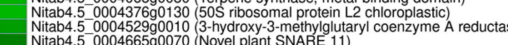

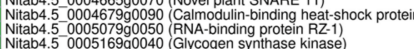

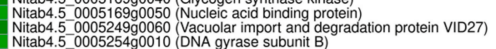

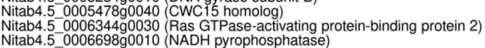

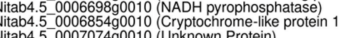

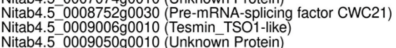

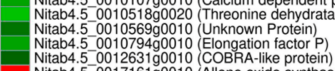

蓄品

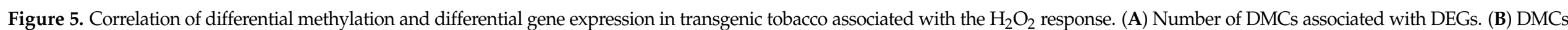

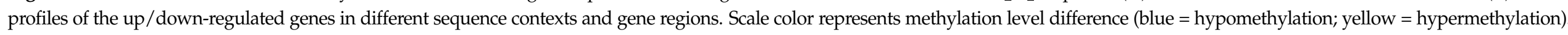

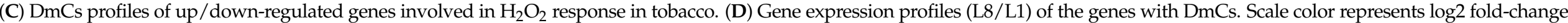
expression (red $=$ upregulation, green $=$ downregulation $)$. 
Figure 5 shows a heatmap of 83 genes with DmC-DEG, where the gene ID number and identity of the gene was aligned with the differential methylation level and the context in each one (Figure 5C), as well as the differential expression (Figure 5D). In most of the genes, a positive correlation was observed, where hypomethylated sites were associated with downregulation expression of genes.

Interestingly, three sRNA genes in the L8 transgenic tobaccos were identified, corresponding to an abortive infection protein, a cytidylyltransferase, and a terpene synthase; and one in the L1 tobaccos matched with a gelsolin.

\section{Discussion}

The present study provides insights into the study of $\mathrm{H}_{2} \mathrm{O}_{2}$ roles with the DNA methylation and their impact on the physiological adaptation to stress factors. The data has high reliability and accuracy. The mapping efficiency obtained is comparable to the informed in other WGBS studies [16,48-50]. Likewise, the proportion of the three-methylation context in the transgenic tobaccos was similar to those reported in other plant models as soybean [51], barrel clover [7], maize [16], Arabidopsis [21,50], tomato [52], burberry [48] and watermelon [49], among others. In all these studies, the higher methylation levels were located in the CG context. Similar results in the distribution of DmC in different genomic regions were obtained by Manoharlal et al. In their study presents a methylometranscriptomic profile of tobacco after gibberellin A3 application [53]. The high number of methylations in intergenic regions may be in part due to the high content of repetitive sequences in the tobacco genome. Thus, part of the differences in the proportion of hypermethylated and hypomethylated regions in their study and ours may be due to the variable of treatment and the transgene, respectively.

Nevertheless, in our data, the most changes in the DmCs sites were in the CHG context. This pattern was also reported in other DNA methylation studies related to stress responses, as salt stress [54]. There has been pointed out that the $\mathrm{CHH}$ hypomethylation had a high relevance in plant defense, and it is related to the RNA-directed DNA methylation pathway [55]. Despite the low number of sRNAs correlated with the WGBS data, some genes DmC-DEG were associated with RNA binging and RNA metabolism. Also, it is possible that exists other sequences of non-coding RNAs not identified among the sites with differential methylation on intergenic regions, which was the most abundant in this study. The non-coding RNAs play a critical role in the transcriptional and posttranscriptional regulation of gene expression and lately have emerged as key regulatory elements in the plant stress responses [56].

It is pointed out that the $\mathrm{H}_{2} \mathrm{O}_{2}$ can induce stress tolerance in plants when applied exogenously, and due to several redox-sensitive genes are involved in stress acclimation [27]. Similarly, recent evidence indicates a close relationship between the ROS regulation and the epigenetic regulation in a negative association. In several studies has been suggested that ROS accumulation causes DNA hypomethylation $[47,57,58]$. Our data agree with these assumptions, considering that most DmCs were hypomethylated. It suggested that the $\mathrm{H}_{2} \mathrm{O}_{2}$ overproduction provokes a new methylation status in the genome, according to the necessities of the system to reach a balance. Due to this, the functional linkages pointed out by the GO analysis categories were photosynthesis and energy metabolism as the most affected by the DmCs on genes in response to the overproduction of $\mathrm{H}_{2} \mathrm{O}_{2}$. Some genes identified that also exhibited an up-regulation in DEG were associated with proton transport, as the V-type proton ATPase and the ABC transporter-like. These data corroborate that $\mathrm{H}_{2} \mathrm{O}_{2}$, as part of the ROS balance, plays a crucial role in the physiological adaptation of plants, such that the plant under continuous oxidative stress has reached a balanced state where the ROS metabolism has been adjusted through the respiration and energy processes.

Additionally, it has been demonstrated that $\mathrm{H}_{2} \mathrm{O}_{2}$ has a strong link with calcium signaling on gene expression regulation, antioxidant defense, and development modulation. Crosstalk among them is given in stress responses when $\mathrm{H}_{2} \mathrm{O}_{2}$ can activate calcium 
channels and calcium-dependent protein kinases. [59-61]. Furthermore, $\mathrm{H}_{2} \mathrm{O}_{2}$ can play a key function on DNA methylation for the activation of genes related to calcium as it is suggested by the presence of DmC-DEG in genes as the calcium-binding protein 39, the gelsolin, calmodulin-binding heat-shock protein, calcium-dependent protein kinase. Calcium participates in the cell signaling pathways, and it is considered as a sensor to external stimulus. Moreover, some DmC-DEG genes were associated with membrane transport, as the adaptor protein complex involved in the protein transport and related to the recruitment of clathrins and recognition of cargo molecules. In the study of Atighi et al. it was suggested that DNA hypomethylation is part of the general plant patterntriggered immunity defense responses due to their inverse association with susceptibility to nematodes [62], such that there was a strong relationship with the recognition, molecule transport, and signaling process and changes in DNA methylation.

In the study performed by Cao et al. it was reported that $\mathrm{H}_{2} \mathrm{O}_{2}$ pretreatment-triggered DNA methylation variations, which may alleviate methylation and damage induced by heat stress in cucumber. Even when this analysis was limited to MSAP loci, it emphasized the relevance of $\mathrm{H}_{2} \mathrm{O}_{2}$ to enhance or inhibit gene transcript levels by the effect methylation changes [34]. Among the genes DmC-DEG associated with stress responses, the legume lectin, the armadillo-like protein, and SNARE11 were identified in our data. Also, two genes related to the methylation process (5-methyltetrahydropteroyltriglutamate -homocysteine methyltransferase and histone-lysine N-methyltransferase) and three associated with DNA repair (ATMRK serine-threonine protein kinase-like, Telomerase activating protein, DNA mismatch repair protein) were found. Also, the presence of some genes associated with RNA binding proteins and nucleic acid binding proteins suggested that the $\mathrm{H}_{2} \mathrm{O}_{2}$, despite related to DNA damage, the continuous $\mathrm{H}_{2} \mathrm{O}_{2}$ levels in the plant activate the mechanisms to protect the genetic material of the individual.

Although large-scale changes in the DNA methylation status, and either a wide number of genes stress-related within the genes with DmC and DEG were not found, some changes in the protein-coding regions with DmCs identified in the study. In our case, there was a low coincidence with the transcriptomic data due to the different depth coverage of the omics data obtained in each profile. Further studies will be carried out to confirm the expression of some of these genes in the transgenic plant, to validate the data obtained by WGBS.

Taken together, the data obtained in the present study strongly suggest that the $\mathrm{H}_{2} \mathrm{O}_{2}$ overproduction in the transgenic tobacco could be associated with rapid recognition of stress and triggering of defense responses, which may be critical in the well-timed activation of the defense system and by consequence, in the physiological adaptation to stress. This is related to the study of Zhou et al., in where spaceflight induced a significant number of genes DmC-DEG associated with ROS signaling, demonstrating that ROS genes play a fundamental role in the physiological adaptation of plants to stress [21]. Considering that the spaceflight environment is a unique and unconventional stress condition, they highlighted the importance of the ROS signaling in the shaped responses to stress, which made them a critical point to stimulate the adaptation of the crops to a more changing and unpredictable environment. Finally, the whole-genome differential cytosine methylation found between the two transgenic tobacco lines helps explain the differential phenotype related to stress response displayed by these plants; moreover, suggesting that an epigenetic component at cytosine DNA methylation it is important in the phenomenon.

\section{Materials and Methods}

\subsection{Transgenic Plants Growth Conditions}

Seeds from the transgenic lines L8 (overproducing $\mathrm{H}_{2} \mathrm{O}_{2}$ ) and L1 (acigotic line) obtained in previous works were used [41]. The seeds were surface sterilized by immersion in $10 \%$ sodium hypochlorite solution for $5 \mathrm{~min}$ and washed three times with sterile distilled water. The seeds were left in sterile water for three days; then 20 seeds of each line were sowed in flasks with Murashige-Skoog medium with $100 \mu \mathrm{g} / \mathrm{mL}$ of kanamycin as a selec- 
tion agent for the transgene. They were kept at room temperature under a $16 \mathrm{~h}$ light $/ 8 \mathrm{~h}$ dark photoperiod. After three weeks the seedlings were transferred into individual pots with Mixture 3 Peat Moss Sunshine as substrate and kept inside a glass chamber at room temperature with humidity of $70 \%$ for three days. They were kept in a greenhouse until seed obtaining. The plants were watered daily.

\subsection{Tissue Sampling and Physiological Testing}

Three 6-weeks-old plants of each group were selected randomly for sampling. The leaves of each plant were cute and frozen in liquid nitrogen and stored at $-70{ }^{\circ} \mathrm{C}$. For the physiological analysis, 6-weeks and three-month-old plants were measured for height, fresh weight, dry weight, stem width, foliar area, and chlorophyll content approximation by a SPAD meter.

\subsection{DNA Extraction}

Genomic DNA was extracted from $200 \mathrm{mg}$ of leaf tissue of each sample, which was pulverized with liquid nitrogen. Extractions were carried out by the cetyltrimethylammonium bromide (CTAB) method [37]. DNA purity and concentration were measured in a Nanodrop spectrophotometer (Accesolab, Mexico City, Mexico), and DNA quality was verified by electrophoresis using $1.2 \%$ agarose gel stained with RedGel.

\subsection{WGBS}

A total of six DNA samples (three individuals per group) were sent for whole-genome bisulfite sequencing (WGBS) to the Beijing Genomic Institute (BGI, Beijing, China). The library preparation was done according to the BGI standard directional WGBS pipeline. Genome fragmentation into 100-300 bp fragments was done by sonication. Bisulfite treatment was done with the EZ DNA methylation Gold Kit (ZYMO, Mexico City, Mexico). The WGBS consisted of a 150 bp paired-end sequencing with a genome coverage of $12 \times$ on a NovaSeq 6000 system (Illumina, Inc., San Diego, CA, USA).

\subsection{Data Processing}

Raw reads were pre-processed with the Fastp v0.20.0 [63] using $-\mathrm{c}-\mathrm{x}-\mathrm{y}$ options for polyX trimming in $3^{\prime}$ ends, base correction in overlapped regions, and low complexity filtering, respectively. Clean reads were aligned to the $N$. tabacum reference genome (EBI: AWOJ01000000) using Bismark aligner v0.22.3 [64] under the parameters - N 1 - L 20 -bowtie2 -nondirectional. The resulting BAM files were sorted and indexed using Samtools v1.9 [65]. Subsequently, the differential methylation analysis was performed using Methylkit v1.14.2 [66] in R v4.0.0 [67] as follows: Methylated cytosines were extracted from aligned reads using processBismarkAln function. To filter bases above the background expected from inefficiencies in the bisulfite conversion reaction and sequencing errors, the filterByCoverage function was used to discard bases that have coverage below 10X and discard the bases that have more than 99.9th percentile of coverage in each sample. The parameters for the calculated DiffMeth function were slim $=$ TRUE, weighted. mean $=$ TRUE. Differential methylated cytosines $($ DmC) were defined as cytosines that had q-value $<0.01$ and methylation difference $>25 \%$ between L1 (control) and L8 (test) methylation rates. Only was considered DmC present in the 3 biological replicates to made more rigorous our methylation changes detection. Gene ontology enrichment analysis was performed with R package clusterProfiler [68], selecting significant GO categories with q-value $<0.05$.

\subsection{Correlation between DmC and DEGs}

For analyzing the relationship between the differential methylated cytosines (DmC) obtained in this study and the genes with differential expression (DEGs) obtained in previous work [42]. The data was graphic with $\mathrm{R}$ package heatmap. 


\subsection{Statistics and Data Visualization}

The graphs were generated with R software. An ANOVA analysis was performed in $\mathrm{R}$ using the ANOVA function in the stats package and Duncan's multiple range test.

\subsection{Data Availability}

Bisulfite sequencing data reported in this study are available under the GSE161166 series accession number at the Gene Expression Omnibus (GEO) database.

\section{Conclusions}

$\mathrm{H}_{2} \mathrm{O}_{2}$ overproduction in the transgenic tobacco plants has a high impact on the cytosine DNA methylation status of associated genes, especially with CHG context changes on the gene body regions. The impact was observed in energy metabolism genes, molecule transport, sensing, and signaling related to calcium and DNA repair. This work corroborates that the $\mathrm{H}_{2} \mathrm{O}_{2}$ is a key compound in the biological process, with a molecular significance at an epigenetic level.

Supplementary Materials: The following are available online at https:/ /www.mdpi.com/2223-7 747/10/1/178/s1. Table S1: Statistics Results of data production, Figure S1: Alignment with the reference genome, Figure S2: Enrichment analysis of gene ontology terms of the biological process, cellular components, and molecular function categories, Table S2: Regions in exons hypermethylated in L8 transgenic line, Table S3: Regions in exons hypomethylated in L8 transgenic line.

Author Contributions: A.L.V.-A. has done the original draft preparation and editing and the investigation and formal analysis. L.F.G.-O. have done the data curation, formal computational analysis; and provided the computational resources. I.T.-P., carried out critical reading of the first manuscript draft and the final manuscript. R.G.G.-G. oversaw the draft, conceptualization, methodology, validation, resources, supervision, funding acquisition, and project administration. All authors have read and agreed to the published version of the manuscript. Authorship must be limited to those who have contributed substantially to the work reported.

Funding: The SEP-CONACYT Basic Science funded this research and the APC grant number 283259.

Institutional Review Board Statement: Not applicable.

Informed Consent Statement: Not applicable.

Data Availability Statement: Bisulfite sequencing data reported in this study are available under the GSE161166 series accession number at the Gene Expression Omnibus (GEO) database.

Acknowledgments: The authors gratefully acknowledge the computing time granted by the IPICYT Supercomputing National Center for Education \& Research (CNS-IPICYT), grant TKII-R2020-LFGO. Additionally, A.L.V.A. shows gratitude to the Consejo Nacional de Ciencia y Tecnología (CONACYT) for providing the Postgrad Scholarship (No. 714246).

Conflicts of Interest: The authors declare no conflict of interest. The funders had no role in the design of the study; in the collection, analyses, or data interpretation; in manuscript writing, or in the decision to publish the results.

\section{References}

1. Kapazoglou, A.; Ganopoulos, I.; Tani, E.; Tsaftaris, A. Epigenetics, Epigenomics and Crop Improvement. Adv. Bot. Res. 2018, 86, 287-324. [CrossRef]

2. Lämke, J.; Bäurle, I. Epigenetic and chromatin-based mechanisms in environmental stress adaptation and stress memory in plants. Genome Biol. 2017, 18, 1-11. [CrossRef] [PubMed]

3. Balao, F.; Paun, O.; Alonso, C. Uncovering the contribution of epigenetics to plant phenotypic variation in Mediterranean ecosystems. Plant Biol. 2018, 20, 38-49. [CrossRef] [PubMed]

4. Avramova, Z. Transcriptional 'memory' of a stress: Transient chromatin and memory (epigenetic) marks at stress-response genes. Plant J. 2015, 83, 149-159. [CrossRef]

5. Karanthamalai, J.; Chodon, A.; Chauhan, S.; Pandi, G. DNA N6-Methyladenine Modification in Plant Genomes-A Glimpse into Emerging Epigenetic Code. Plants 2020, 9, 247. [CrossRef]

6. Manova, V.; Gruszka, D. DNA damage and repair in plants-From models to crops. Front. Plant Sci. 2015, 6, 1-26. [CrossRef] 
7. Yaish, M.W.; Al-Lawati, A.; Al-Harrasi, I.; Patankar, H.V. Genome-wide DNA Methylation analysis in response to salinity in the model plant caliph medic (Medicago truncatula). BMC Genom. 2018, 19, 1-17. [CrossRef]

8. Asensi-Fabado, M.-A.; Amtmann, A.; Perrella, G. Plant responses to abiotic stress: The chromatin context of transcriptional regulation. Biochim. Biophys. Acta (BBA) Bioenerg. 2017, 1860, 106-122. [CrossRef]

9. Holeski, L.M.; Jander, G.; Agrawal, A.A. Transgenerational defense induction and epigenetic inheritance in plants. Trends Ecol. Evol. 2012, 27, 618-626. [CrossRef]

10. Pastor, V.; Luna, E.J.; Mauch-Mani, B.; Ton, J.; Flors, V. Primed plants do not forget. Environ. Exp. Bot. 2013, 94, 46-56. [CrossRef]

11. Gallusci, P.; Dai, Z.; Génard, M.; Gauffretau, A.; Leblanc-Fournier, N.; Richard-Molard, C.; Vile, D.; Brunel-Muguet, S. Epigenetics for Plant Improvement: Current Knowledge and Modeling Avenues. Trends Plant Sci. 2017, 22, 610-623. [CrossRef] [PubMed]

12. Kaur, A.; Grewal, A.; Sharma, P. Comparative analysis of DNA methylation changes in two contrasting wheat genotypes under water deficit. Biol. Plant 2018, 62, 471-478. [CrossRef]

13. Bilichak, A.; Ilnystkyy, Y.; Hollunder, J.; Kovalchuk, I. The Progeny of Arabidopsis thaliana Plants Exposed to Salt Exhibit Changes in DNA Methylation, Histone Modifications and Gene Expression. PLoS ONE 2012, 7, e30515. [CrossRef] [PubMed]

14. Tang, X.; Wang, Q.; Huang, X. Chilling-induced DNA Demethylation is associated with the cold tolerance of Hevea brasili-ensis. BMC Plant Biol. 2018, 18, 1-16. [CrossRef] [PubMed]

15. Xin, C.; Chi, J.; Zhao, Y.; He, Y.; Guo, J. Cadmium stress alters cytosine methylation status and expression of a select set of genes in Nicotiana benthamiana. Plant Sci. 2019, 284, 16-24. [CrossRef]

16. Mager, S.; Ludewig, U. Massive Loss of DNA Methylation in Nitrogen-, but Not in Phosphorus-Deficient Zea mays Roots Is Poorly Correlated with Gene Expression Differences. Front. Plant Sci. 2018, 9, 497. [CrossRef]

17. Kou, H.P.; Li, Y.; Song, X.X.; Ou, X.F.; Xing, S.C.; Ma, J.; von Wettstein, D.; Liu, B. Heritable alteration in DNA methylation induced by nitrogen-deficiency stress accompanies enhanced tolerance by progenies to the stress in rice (Oryza sativa L.). J. Plant Physiol. 2011, 168, 1685-1693. [CrossRef]

18. Lewandowska-Gnatowska, E.; Polkowska-Kowalczyk, L.; Szczegielniak, J.; Barciszewska, M.; Barciszewski, J.; Muszyńska, G. Is DNA methylation modulated by wounding-induced oxidative burst in maize? Plant Physiol. Biochem. 2014, 82, 202-208. [CrossRef]

19. Wang, C.; Wang, C.; Xu, W.; Zou, J.; Qiu, Y.; Kong, J.; Yang, Y.; Zhang, B.; Zhu, S. Epigenetic Changes in the Regulation of Nicotiana tabacum Response to Cucumber Mosaic Virus Infection and Symptom Recovery through Single-Base Resolution Methylomes. Viruses 2018, 10, 402. [CrossRef]

20. Luo, J.-Y.; Pan, X.-L.; Peng, T.-C.; Chen, Y.-Y.; Zhao, H.; Mu, L.; Peng, Y.; He, R.; Tang, H. DNA methylation patterns of banana leaves in response to Fusarium oxysporum f. sp. cubense tropical race 4. J. Integr. Agric. 2016, 15, 2736. [CrossRef]

21. Zhou, M.; Sng, N.J.; Le Frois, C.; Paul, A.-L.; Ferl, R.J. Epigenomics in an extraterrestrial environment: Organ-specific alteration of DNA methylation and gene expression elicited by spaceflight in Arabidopsis thaliana. BMC Genom. 2019, 20, 205. [CrossRef] [PubMed]

22. Kuźnicki, D.; Meller, B.; Arasimowicz-Jelonek, M.; Brąszewska, A.; Drozda, A.; Floryszak-Wieczorek, J. BABA-Induced DNA Methylome Adjustment to Intergenerational Defense Priming in Potato to Phytophthora infestans. Front. Plant Sci. 2019, 10, 1-16. [CrossRef] [PubMed]

23. Bertini, L.; Proietti, S.; Focaracci, F.; Sabatini, B.; Caruso, C. Epigenetic control of defense genes following MeJA-induced priming in rice. J. Plant Physiol. 2018, 228, 166-177.

24. Smirnoff, N.; Arnaud, D. Hydrogen peroxide metabolism and functions in plants. New Phytol. 2018, 221, 1197-1214. [CrossRef]

25. Mittler, R. ROS Are Good. Trends Plant Sci. 2017, 22, 11-19. [CrossRef]

26. Qi, J.; Wang, J.; Gong, Z.; Zhou, J.M. Apoplastic ROS signaling in plant immunity. Curr. Opin. Plant Biol. 2017, 38, 92-100. [CrossRef]

27. Hossain, M.A.; Bhattacharjee, S.; Armin, S.-M.; Qian, P.; Xin, W.; Li, H.-Y.; Burritt, D.J.; Fujita, M.; Tran, L.P. Hydrogen peroxide priming modulates abiotic oxidative stress tolerance: Insights from ROS detoxification and scavenging. Front. Plant Sci. 2015, 6, 420. [CrossRef]

28. Wahid, A.; Perveen, M.; Gelani, S.; Basra, S.M. Pretreatment of seed with H2O2 improves salt tolerance of wheat seedlings by alleviation of oxidative damage and expression of stress proteins. J. Plant Physiol. 2007, 164, 283-294. [CrossRef]

29. Christou, A.; Manganaris, G.A.; Fotopoulos, V. Systemic mitigation of salt stress by hydrogen peroxide and sodium nitroprusside in strawberry plants via transcriptional regulation of enzymatic and non-enzymatic antioxidants. Environ Exp Bot. 2014, 107, 46-54. [CrossRef]

30. Ellouzi, H.; Sghayar, S.; Abdelly, C. H2O2 seed priming improves tolerance to salinity; drought and their combined effect more than mannitol in Cakile maritima when compared to Eutrema salsugineum. J. Plant Physiol. 2017, 210, 38-50. [CrossRef]

31. Bagheri, M.; Gholami, M.; Baninasab, B. Hydrogen peroxide-induced salt tolerance in relation to antioxidant systems in pis-tachio seedlings. Sci. Hortic. 2019, 243, 207-213. [CrossRef]

32. Sun, Y.; Wang, H.; Liu, S.; Peng, X. Exogenous application of hydrogen peroxide alleviates drought stress in cucumber seedlings. S. Afr. J. Bot. 2016, 106, 23-28. [CrossRef]

33. Ishibashi, Y.; Yamaguchi, H.; Yuasa, T.; Iwaya-Inoue, M.; Arima, S.; Zheng, S.-H. Hydrogen peroxide spraying alleviates drought stress in soybean plants. J. Plant Physiol. 2011, 168, 1562-1567. [CrossRef] [PubMed]

34. Cao, Y.-Y.; Gao, Y.; Sun, W.-J.; Huang, Y.-W.; Zhang, J.; Bai, J.-G. Role of hydrogen peroxide pretreatment in heat-induced alteration of DNA methylation in cucumber leaves. Sci. Hortic. 2013, 151, 173-183. [CrossRef] 
35. Gao, Y.; Guo, Y.-K.; Lin, S.-H.; Fang, Y.-Y.; Bai, J.-G. Hydrogen peroxide pretreatment alters the activity of antioxidant enzymes and protects chloroplast ultrastructure in heat-stressed cucumber leaves. Sci. Hortic. 2010, 126, 20-26. [CrossRef]

36. Andrade, C.A.; de Souza, K.R.D.; Santos, M.O.; Silva, D.M.; Alves, J.D. Hydrogen peroxide promotes the tolerance of soybeans to waterlogging. Sci. Hortic. 2018, 232, 40-45. [CrossRef]

37. Mejía-Teniente, L.; Durán-Flores, B.A.; Torres-Pacheco, I.; Gonzalez-Chavira, M.M.; Rivera-Bustamante, R.; Feregrino-Perez, A.A.; Pérez-Ramírez, I.; Rocha-Guzmán, N.E.; Reynoso-Camacho, R.; Guevara-Gonzalez, R.G. Hydrogen peroxide protects pepper (Capsicum annuum L.) against pepper golden mosaic geminivirus (PepGMV) infections. Physiol. Mol. Plant Pathol. 2019, 106, 23-29. [CrossRef]

38. Vargas-Hernández, M.; Torres-Pacheco, I.; Gautier, F.; Álvarez-Mayorga, B.; Cruz-Hernández, A.; García-Mier, L.; Jiménez-García, S.N.; Ocampo-Velázquez, R.V.; Feregrino-Perez, A.A.; Guevara-Gonzalez, R.G. Influence of hydrogen peroxide foliar applications on in vitro antimicrobial activity in Capsicum chinense Jacq. Plant Biosyst. Int. J. Deal. all Asp. Plant. Biol. 2016, 151, 269-275. [CrossRef]

39. Zhang, X.-L.; Jia, X.-F.; Yu, B.; Gao, Y.; Bai, J.-G. Exogenous hydrogen peroxide influences antioxidant enzyme activity and lipid peroxidation in cucumber leaves at low light. Sci. Hortic. 2011, 129, 656-662. [CrossRef]

40. Godínez-Hernández, Y.; Anaya-López, J.L.; Díaz-Plaza, R.; González-Chavira, M.; Torres-Pacheco, I.; Rivera-Bustamante, R.F.; Guevara-González, R.G. Characterization of resistance to pepper huasteco geminivirus in chili peppers from Yucatán, México. Hort. Sci. 2001, 36, 139-142.

41. Guevara-Olvera, L.; Ruíz-Nito, M.; Rangel-Cano, R.; Torres-Pacheco, I.; Rivera-Bustamante, R.; Muñoz-Sánchez, C.; González-Chavira, M.; Cruz-Hernandez, A.; Guevara-Gonzalez, R.; Rivera-Bustamante, R. Expression of a germin-like protein gene (CchGLP) from a geminivirus-resistant pepper (Capsicum chinense Jacq.) enhances tolerance to geminivirus infection in transgenic tobacco. Physiol. Mol. Plant Pathol. 2012, 78, 45-50. [CrossRef]

42. Cardenas-Manríquez, G.; Cruz-Hernandez, A.; Torres-Pacheco, I.; Caballero-Pérez, J.; González-Chavira, M.M.; García-Ortega, L.F.; Guevara-González, R.G. Transcriptome profiling of transgenic tobacco (Nicotiana tabacum cv. xanthi nc) expressing CchGLP gene from Capsicum chinense Jacq. reveals gene expression associated with stress tolerance. J. Hortic. Sci. Biotechnol. 2018, 93, 595-604. [CrossRef]

43. Sáenz, O.D.; Cedillo-Jimenez, C.A.; García-Ortega, L.F.; Martínez-Reséndiz, M.; Arné-Robles, D.; Cruz-Hernandez, A.; Guevara-Gonzalez, R.G. Response of transgenic tobacco overexpressing the CchGLP gene to cadmium and aluminium: Phenotypic and microRNAs expression changes. Physiol. Mol. Biol. Plants 2020, 26, 3-13. [CrossRef] [PubMed]

44. Cárdenas-Manríquez, G.; Vega-Muñoz, I.; Villagómez-Aranda, A.; León-Galvan, M.; Cruz-Hernandez, A.; Torres-Pacheco, I.; Rangel-Cano, R.; Rivera-Bustamante, R.; Guevara-Gonzalez, R.G.; Rivera-Bustamante, R. Proteomic and metabolomic profiles in transgenic tobacco (N. tabacum xanthi nc) to CchGLP from Capsicum chinense BG-3821 resistant to biotic and abiotic stresses. Environ. Exp. Bot. 2016, 130, 33-41. [CrossRef]

45. Cárdenas-Manríquez, G.; Robles-Bustos, D.A.; Vega-Muñoz, I.; Villagómez-Aranda, A.L.; Torres-Pacheco, I.; Guevara-Gonzalez, R.G. Determination of molecular communication network in transgenic tobbaco expressing CchGLP gene. In Proceedings of the 2017 XIII International Engineering Congress (CONIIN), Santiago de Queretaro, Mexico, 15-19 May 2017; pp. 1-9. [CrossRef]

46. Locato, V.; Cimini, S.; De Gara, L. ROS and redox balance as multifaceted players of cross-tolerance: Epigenetic and retrograde control of gene expression. J. Exp. Bot. 2018, 69, 3373-3391. [CrossRef]

47. Saravana Kumar, R.M.; Wang, Y.; Zhang, X.; Cheng, H.; Sun, L.; He, S.; Hao, F. Redox components: Key regulators of epigenetic modifications in plants. Int. J. Mol. Sci. 2020, 21, 1419.

48. Li, R.; Hu, F.; Li, B.; Zhang, Y.; Chen, M.; Fan, T.; Wang, T. Whole genome bisulfite sequencing methylome analysis of mulberry (Morus alba) reveals epigenome modifications in response to drought stress. Sci. Rep. 2020, 10, 1-17. [CrossRef]

49. Sun, Y.; Fan, M.; He, Y. DNA Methylation Analysis of the Citrullus lanatus Response to Cucumber Green Mottle Mosaic Virus Infection by Whole-Genome Bisulfite Sequencing. Genes 2019, 10, 344. [CrossRef]

50. Fan, S.K.; Ye, J.Y.; Zhang, L.L.; Chen, H.S.; Zhang, H.H.; Zhu, Y.X.; Liu, X.X.; Jin, C.W. Inhibition of DNA demethylation enhances plant tolerance to cadmium toxicity by improving iron nutrition. Plant Cell Environ. 2019, 43, 275-291. [CrossRef]

51. Ji, L.; Mathioni, S.M.; Johnson, S.; Tucker, D.; Bewick, A.J.; Kim, K.D.; Daron, J.; Slotkin, R.K.A.; Jackson, S.; Parrott, W.; et al. Genome-Wide Reinforcement of DNA Methylation Occurs during Somatic Embryogenesis in Soybean. Plant Cell 2019, 31, 2315-2331. [CrossRef]

52. Zuo, J.; Wang, Y.; Zhu, B.; Luo, Y.; Wang, Q.; Gao, L. Comparative Analysis of DNA Methylation Reveals Specific Regulations on Ethylene Pathway in Tomato Fruit. Genes 2018, 9, 266. [CrossRef] [PubMed]

53. Manoharlal, R.; Saiprasad, G.V.S.; Kaikala, V.; Kumar, R.S.; Kovarik, A. Analysis of DNA methylome and transcriptome profiling following Gibberellin A3 (GA3) foliar application in Nicotiana tabacum L. Indian J. Plant Physiol. 2018, 23, 543-556. [CrossRef]

54. Konate, M.; Wilkinson, M.J.; Mayne, B.T.; Pederson, S.M.; Scott, E.S.; Berger, B.; Lopez, C.R. Salt Stress Induces Non-CG Methylation in Coding Regions of Barley Seedlings (Hordeum vulgare). Epigenomes 2018, 2, 12. [CrossRef]

55. Gallego-Bartolomé, J. DNA methylation in plants: Mechanisms and tools for targeted manipulation. New Phytol. 2020, 227, 38-44. [CrossRef]

56. Wang, J.; Meng, X.; Dobrovolskaya, O.B.; Orlov, Y.L.; Chen, M. Non-coding RNAs and Their Roles in Stress Response in Plants. Genom. Proteom. Bioinform. 2017, 15, 301-312. [CrossRef] [PubMed] 
57. Sano, H.; Choi, S.C. Abiotic-stress induces demethylation and transcriptional activation of a gene encoding a glycerophosphodiesteraselike protein in tobacco plants. Mol. Genet. Genom. 2007, 277, 589-600.

58. Poborilova, Z.; Ohlsson, A.B.; Berglund, T.; Vildova, A.; Provaznik, I.; Babula, P. DNA hypomethylation concomitant with the overproduction of ROS induced by naphthoquinone juglone on tobacco BY-2 suspension cells. Environ. Exp. Bot. 2015, 113, 28-39. [CrossRef]

59. Niu, L.; Liao, W. Hydrogen Peroxide Signaling in Plant Development and Abiotic Responses: Crosstalk with Nitric Oxide and Calcium. Front. Plant Sci. 2016, 7, 1-14. [CrossRef]

60. Habibi, G. Hydrogen Peroxide (H2O2) Generation, Scavenging and Signaling in Plants. Oxid. Damage Plants 2014, 557-584.

61. Smékalová, V.; Doskočilová, A.; Komis, G.; Šamaj, J. Crosstalk between secondary messengers, hormones and MAPK modules during abiotic stress signalling in plants. Biotechnol. Adv. 2014, 32, 2-11. [CrossRef]

62. Atighi, M.R.; Verstraeten, B.; De Meyer, T.; Kyndt, T. Genome-wide DNA hypomethylation shapes nematode pattern-triggered immunity in plants. New Phytol. 2020, 227, 545-558. [CrossRef] [PubMed]

63. Chen, S.; Zhou, Y.; Chen, Y.; Gu, J. Fastp: An ultra-fast all-in-one FASTQ preprocessor. Bioinformatics 2018, 34, i884-i890. [CrossRef] [PubMed]

64. Krueger, F.; Andrews, S.R. Bismark: A flexible aligner and methylation caller for Bisulfite-Seq applications. Bioinformatics 2011, 27, 1571-1572. [CrossRef]

65. Li, H.; Handsaker, B.; Wysoker, A.; Fennell, T.; Ruan, J.; Homer, N.; Marth, G.; Abecasis, G.; Durbin, R.; Project, G.; et al. The Sequence Alignment/Map format and SAMtools. Bioinformatics 2009, 25, 2078-2079. [CrossRef] [PubMed]

66. Akalin, A.; Kormaksson, M.; Li, S.; Garrett-Bakelman, F.E.; Figueroa, M.E.; Melnick, A.; Mason, C.E. methylKit: A comprehensive $\mathrm{R}$ package for the analysis of genome-wide DNA methylation profiles. Genome Biol. 2012, 13, R87. [CrossRef]

67. Ihaka, R.; Gentleman, R. R: A Language for Data Analysis and Graphics. J. Comput. Graph. Stat. 1996, 5, $299-314$.

68. Yu, G.; Wang, L.-G.; Han, Y.; He, Q.-Y. clusterProfiler: An R Package for Comparing Biological Themes Among Gene Clusters. OMICS J. Integr. Biol. 2012, 16, 284-287. [CrossRef] 